\title{
Flexible bronchoscopy in very old patients with lung cancer
}

\author{
Eduardo Garcia-Pachon ${ }^{1,2}$ (D) Maria J. Soler-Sempere ${ }^{1}$. Justo Grau-Delgado ${ }^{1}$ Lucia Zamora-Molina ${ }^{1}$. \\ Carlos Baeza-Martinez ${ }^{1}$
}

Received: 20 February 2018 / Accepted: 2 March 2018 / Published online: 12 March 2018

(c) European Geriatric Medicine Society 2018

To the Editor,

Recently, Okachi et al. [1] published in the EuROPEAN GeriATRIC Medicine the results of flexible bronchoscopy in very old patients with lung cancer, and concluded that this technique leads to appropriate treatment decision in this group of patients. Our experience accords with that reported by Okachi et al. [1] in terms of safety and utility of bronchoscopy in octogenarians [2]; and we consider that we can contribute to this conclusion with additional information.

In our series of octogenarian patients who underwent flexible bronchoscopy, lung cancer was eventually diagnosed in $35 \%$ of them [2]. $44 \%$ of these patients were treated with curative intent. Very interestingly, the one-year survival of these patients was of $33 \%$, almost identical to the 1-year survival of lung cancer patients as a whole in our country (36\%) [3].

In view of our findings and those reported by Okachi et al. [1], we can state that the age of the patients could not be considered a criterion for exclusion of further clinical tests in lung cancer suspicion. In view of the safety, diagnostic utility, and prognostic implications, very old patients deserve the adequate clinical evaluation, including bronchoscopy.

\section{Compliance with ethical standards}

Conflict of interest The authors declare that they have no conflict of interest.

Ethical approval The study was approved by the Clinical Research Ethics Committee of the Hospital General Universitario de Elche, Spain.

Informed consent Although specific informed consent was not required for this retrospective study, an informed consent for each bronchoscopy was obtained before the procedure.

\section{References}

1. Okachi S, Imaizumi K, Imai N, Shimizu T, Hase T, Morise M, Hashimoto N, Sato M, Hasegawa Y (2018) Safety and efficacy of diagnostic flexible bronchoscopy in very old patients with lung cancer. Eur Geriatr Med. https://doi.org/10.1007/s4199 9-018-0033-7

2. Noguera-Sanchez A, Soler-Sempere MJ, Grau-Delgado J, ZamoraMolina L, Padilla-Navas I, Garcia-Pachon E (2017) Flexible bronchoscopy in octogenarians. Rev Esp Geriatr Gerontol 52:356

3. Bordoni A, Uhry Z, Antunes L (2017) Trends in net survival lung cancer in six European Latin countries: results from the SUDCAN population-based study. Eur J Cancer Prev. https://doi. org/10.1097/CEJ.0000000000000299

Eduardo Garcia-Pachon

eduardo.garciap@umh.es

1 Section of Respiratory Medicine, Hospital General Universitario de Elche, Elche, Alicante, Spain

2 Department of Clinical Medicine, Universidad Miguel Hernandez, Elche, Alicante, Spain 